\title{
Redes de regadío urbanas y rurales del Bajo Segura en época andalusí. Los casos del Segura y el Chícamo
}

\author{
Manuel de Gea Calatayud, Rafael Moñino Pérez, Patricio Marín Aniorte y Eugenio Marco Tristán
}

museos@rojales.es,rafaeldecox@hotmail.es,p.marinaniorte@hotmail.com,emartri@gmail.com

\begin{abstract}
Resumen. Este artículo es, principalmente, un receso sintético del libro y proyecto de investigación pluridisciplinar: "Los regadíos medievales y su evolución histórica en el Bajo Segura. Poblamiento, poder social y comunidades campesinas" (Gea, Moñino, Marín y Marco, 2011-12). Es por ello, por lo que en sus pocas páginas trataremos de indicar a grandes líneas una visión general de la nueva organización social andalusí vinculada a los espacios irrigados y a la intensificación de la explotación agraria en el entorno de MadinaUryula (Orihuela) y la huerta de Al-Banyala (Abanilla).
\end{abstract}

Palabras clave: huerta, acequia, regadío andalusí, fatwa, Madina Uryula, Chícamo.

\begin{abstract}
This paper summarizes most of the contents of the multidisciplinar research project "Historical Evolution of Medieval Irrigation in the Bajo Segura. Population, social power and peasant communities" (Gea, Moñino, Marín y Marco, 2011-12). In this paper we try to provide a general view of the islamic social organization linked to the irrigated areas and to the intensification of the agrarian exploitations surrounding the city of Madina Uryula (Orihuela) and the market gardens of Al-Banyala (Abanilla).
\end{abstract}

Keywords: buerta, acequia, andalusí irrigation, fatwa, Madina Uryula, Chícamo.

\section{La formación y expansión decisiva de la huerta de Orihuela. El regadío andalusí}

Las características de un río alóctono como el Segura, condicionado por los fuertes estiajes de su régimen antes de ser regulado, han condicionado en buena medida la historia y evolución del valle fluvial y las vegas de Murcia y Orihuela, zonas donde desde la colonización andalusí la ocupación humana tiende a transferir su centro de gravedad. Esta tendencia se efectúa esencialmente sobre la base de una intensificación progresiva de la explotación del suelo, orientando así una nueva ordenación del poblamiento desde las alturas de las alineaciones montañosas hacia las microtopografías del fondo del valle fluvial; tal como acontece en la evolución morfológica de su propia capitalidad urbana UryulaOrihuela.

Para entender esta evolución debemos tratar, en primer lugar, de poner de relieve el meticuloso acondicionamiento hidráulico que va estableciendo la sociedad andalusí en el fondo del valle fluvial, que culminará con la construcción de la red de riego-drenaje principal generadora de un nuevo sistema agro-ecológico: la huerta o área de agricultura de regadío permanente que, en términos generales, es la raíz de la trama del poblamiento tradicional y actual.

Pero, pasemos a ver esto en su contexto histórico originario. Los musulmanes que poblaron nuestra zona fueron gente de origen muy diverso: los árabes de varios países del próximo oriente, fundamentalmente sirio-egipcios y, por tanto, de zonas con importantes ríos y regadíos, pero también bereberes igualmente de origen geográfico y tribal diverso, que habían de formar una nueva sociedad a base de una estrecha relación con la población hispano-romana indígena. Los factores que influyen en este proceso de colonización, 
arabización e islamización son muy variados, presentando unos claros límites étnicos y tribales en un principio, que tendieron a diluirse a lo largo del tiempo.

Es, por tanto, en este contexto donde hay que integrar, en primer lugar, diversas descripciones de geógrafos y autores árabes medievales que consignan, de forma concisa pero esencial, el aspecto geohistórico primordial que acontece en la zona tras la conquista. Estas noticias pensamos que son claves para comprender cómo evoluciona la nueva colonización que cambió de forma progresiva, pero radical, nuestra comarca y el resto de las vegas del Segura (Pocklington, 1989; Gea, 1995). A este respecto Al-Udri afirma:

"El territorio de Tudmir(Orihuela) es famoso por la fecundidad de sus tierras y la exquisitez de sus frutos. Se estableció en ella el yund de Egipto (año 743). Su tierra está regada por un río de iguales propiedades que el Nilo de Egipto".

Y, además, añade:

"El río Tudmir posee norias que riegan las huertas de este territorio".

Al-Maqqari dice:

"La Cora de Tudmir se llama Misr (Egipto), por parecerse mucho a este pais: su río la inunda en una época determinada del año, luego las aguas se alejan y se realiza la siembra como en Egipto".

Anteriormente, Al-Razi, cuya obra, escrita hacia el año 950, que sirvió de fuente directa o indirecta para todas las demás, relaciona el aprovechamiento de las crecidas con los lugares de la Península Ibérica en que contingentes sirio-egipcios del ejército de Baly,se asentaron a mediados del Siglo VIII. Con referencia a Tudemir, dice Al-Razi:

"Et toda su tierra riega el río, assí como faze el río de Nilo en la tierra de promisión".

En efecto, las crecidas de un río alóctono como el Segura, inundaban y enriquecían históricamente los campos del valle fluvial, depositando en ellos el légamo que contenían, el cual, como citan las fuentes históricas: "es increíble lo que vale semejante abono, preferible por muchos respetos al de los estiércoles... En una tierra entarquinada se coge una buena cosecha de trigo con solo un riego que se dé por enero".

Por lo tanto, en paralelo al aprovechamiento de la inundación como sistema de irrigación sin duda de origen preandalusí pero que en esta primera fase de colonización islámica se va a ir mejorando y regulando-, se irá también superponiendo progresivamente (como también confirman las fuentes escritas árabes) una red de regadío ligada al río, a partir del establecimiento del primer complejo de azud-acequia en el área periurbana de Orihuela, configurado mediante la construcción de la Acequia de Los Huertos. Sin duda, ello implicaría establecer una serie de relaciones y pactos entre el poder local y determinados segmentos de la sociedad musulmana: principalmente una serie de nuevos linajes de notables y hacendados locales (como los BanüJattāb que absorben por casamiento la descendencia del señor de Orihuela Teodomiro), que cederán sus fincas irrigadas a campesinos mediante contratos de muحāra'a (aparcería) y, a su vez, con comunidades de campesinos organizados sobre una base clánica, como pasos previos a la construcción de estos conjuntos azud-acequia; los cuales, a su vez, incluirían otros acuerdos sobre la gestión y vigilancia socio-institucional de las aguas así reguladas. Y, especialmente, por las características de la vega fluvial -y esto es también muy importante observarlo-, se deberá ir articulando, unida a la organización general del regadío, una serie de mecanismos de 
defensa y diseminación de avenidas para poder ir generando los nuevos espacios de explotación intensiva del valle fluvial (Gea, 1997, Gea et al., 2011-12).

De esta forma, una vez que la ciudad/madina de Orihuela se configura como lugar estratégico adecuado al nuevo poder andalusí, se va transformando en la ciudad hegemónica del valle del Segura, como resultado de un episodio de colonización agraria premeditado y progresivo, mediante nuevos cultivos y técnicas agrarias que condujeron a una nueva agricultura. El arroz, la caña de azúcar, el algodón, la naranja, la sandía, la berenjena, la palmera de coco, el trigo duro y otras plantas, fueron difundidos en occidente, junto a la transferencia de las nuevas técnicas hidráulicas. Hay que significar que todas estas plantas difundidas en occidente por los musulmanes eran originarias de climas tropicales o semi-tropicales, donde había intensas lluvias en la época de crecimiento, y no podrían, por tanto, cultivarse en nuestro clima mediterráneo sin regadío (Watson, 1998).

La creación de la huerta va adquiriendo un ritmo más uniforme a partir de una mayor influencia y acción del Estado cordobés, en paralelo al mayor auge económico y demográfico de las ciudades del sur, que proporcionan al Emirato, en el siglo IX, el poder financiero necesario para instaurar un sistema de control administrativo y económico más intenso; lo que en nuestro ámbito geográfico estudiado coincide con la fundación de la nueva ciudad de Murcia, en el año 825, por Abderramán II.

A partir de este momento, los espacios periurbanos o interurbanos se irán ordenando en relación a la formación del sistema de riego-drenaje, que parte directamente del río. Sistema articulado a través de una complicada estructura técnica de esclusas y una red de acueductos que se va adaptando a la ley de la gravedad y a la microtopografía que exige la zona, siguiendo en líneas generales los métodos de los ríos orientales en cuanto a tecnología (complejos azud-acequia, norias, cenias, etc.) y distribución del agua. Esta red de riego se va construyendo en su mayor parte en las "tierras altas" del llano aluvial, a salvo de la mayor parte de las crecidas del río, e irá incardinando toda una serie de nuevos núcleos de hábitats rurales o potenciando los existentes. Desde entonces la transformación del valle fluvial en torno a Murcia y Orihuela es tan grande, que supone la creación de un nuevo ecosistema de agricultura intensiva, con bancales cultivados como si fueran jardines.

El sistema de regadío se evidencia decisivamente implantado, cuando el geógrafo Al-Udri describe, en la primera mitad del siglo XI (Periodo de Taifas), que estaba articulada una amplia zona de la Huerta entre Alcantarilla, Murcia y Beniel, por un lado, y Orihuela, Callosa, Catral y Almoradí, por otro, con lo que se confirma que los hinterlands agrícolas de Murcia y Orihuela ya se tocaban entre sí; el sistema estaba pues, preparado para las sucesivas ampliaciones posteriores. Y, de la misma forma, para seguir articulando la trama original del poblamiento actual de la Huerta de la Vega Baja del Segura.

En efecto, Al-Udri no solo identifica la articulación de la red principal de la margen izquierda bajosegureña sino que también verifica algunas claves sobre la interacción espacial urbana y rural y, sobre todo, la plurifuncionalidad urbana de Orihuela respecto a su vega huertana:

"...Después los habitantes de la ciudad de Oribuela empiezan a sacar una acequia de este río de sus tierras (de sus parajes) basta que termina (la acequia) bacia el lugar llamado Al-Qatrullat (Catral). El largo y amplitud de esta acequia es de 28 millas. Y se termina el sistema de agua (sistema de acequias) en el sur (en el lugar opuesto) a un distrito que se llama Al-Muwalladín (coincide espacialmente con el término de Almoradi) y a una alquería que se llama la isla (Al-Yazirab). De alli el río se dirige hacia el mar, siendo conocido aquel lugar con el nombre de Al-Mudáwwar". 
De lo que se puede inferir, evidentemente, cómo Madina Uryula ejerce de elemento motor a partir del cual se ordena su territorio, desplegando un control tanto geopolítico como económico sobre la zona: primero planifica y produce su espacio de riego periurbano que abastece su huerta inmediata y, alternativamente, contribuye a que el resto del área rural citada diseñe y produzca sus espacios irrigados (Gea, 1997) (Fig. 1).

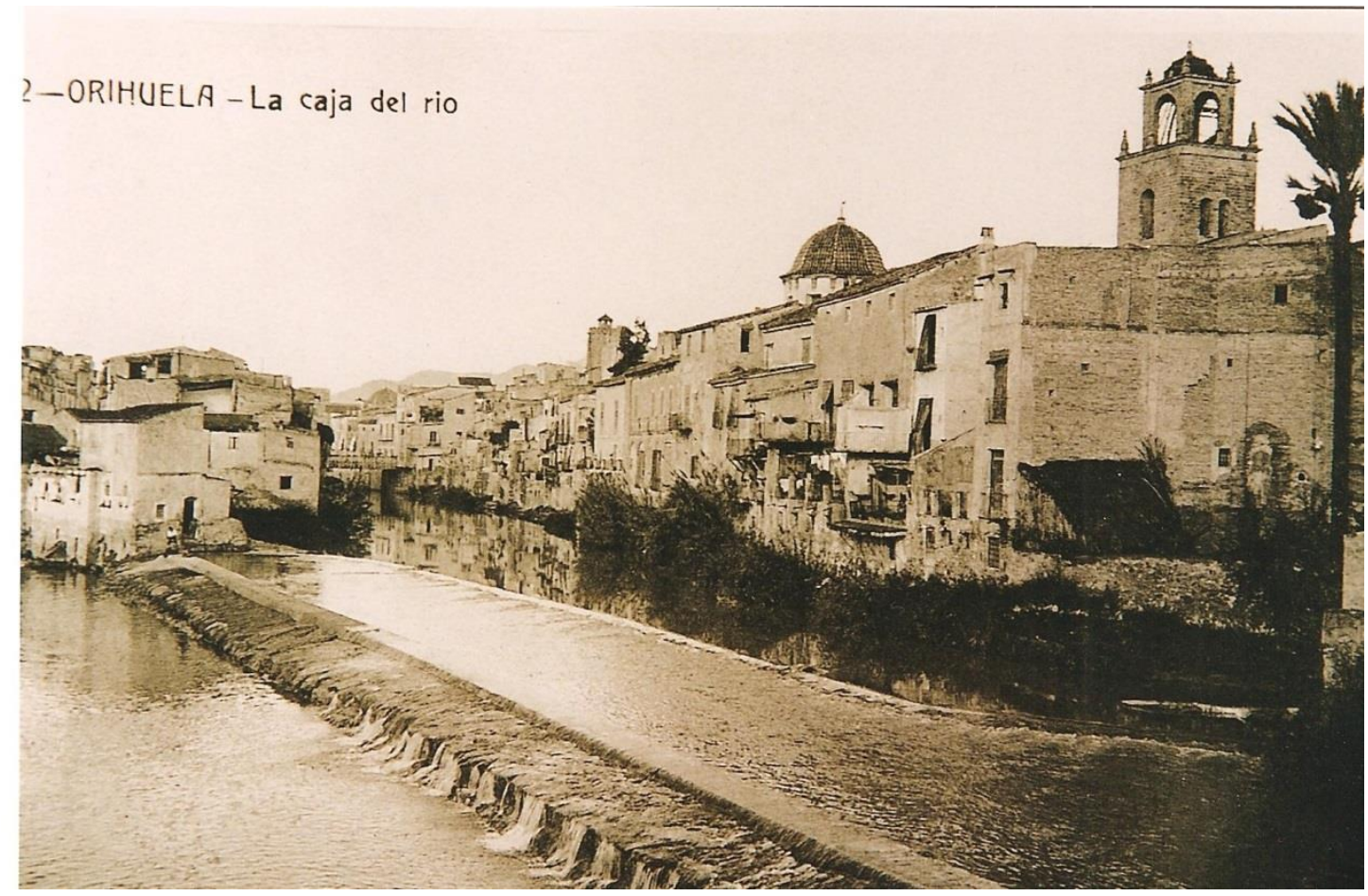

Fig. 1. Foto de Orihuela (de principios del s. XX) en la que se destaca el río Segura bordeando su casco urbano. Obsérvese en primer término la situación urbana de este enclave central del regadío (de origen andalusî), en el que siguen situándose los azudes que suministran aguas a las Acequias Vieja de Almoradí, de Escorratel, Almoravit y de Callosa y Catral.

Por consiguiente, según se desprende del reactivo contexto histórico y espacial, será éste el esquema fundacional unitario, comunitario y colectivo, de la macro-red de riego medieval, cuyos conflictos por el control del agua y la construcción de acequias estructurantes del poblamiento rural segureño, irán requiriendo de una mayor intervención municipal, acorde también con una sociedad en transición hacia un modelo urbano islamizado. Esto, en todo caso, no es nada excepcional en la documentación árabe, en donde se explicitan acuerdos institucionales entre usuarios individuales o alquerías (comunidades de regantes) y los órganos municipales dependientes del Estado.

Las evidencias identifican que, normalmente, las comunidades de regantes actuaban con autonomía del poder central (municipal) a partir de sus órganos y ordenanzas establecidas por ellas mismas y ratificándolos después el qadi, si bien en asuntos de pleitos o desacuerdos este último también ejercía su control a través de funcionarios urbanos que dependían de su administración (y de su ratificación) (López y Martín-Caro, 1989, II; Espinar, 1990). De hecho, T. F. Glick (2007), considerando estos documentos de forma global, señala que nos revelan una dinámica social y política de acuerdos que tienen una naturaleza básicamente estándar y, a la vista de la ultraestabilidad de los sistemas de irrigación, cabe presumir que representan pactos de larga duración. 
Es, por tanto, ante todas estas nuevas dinámicas agrarias, políticas y económicas cuando aparecen nuevos factores esenciales que forman parte también de la aceleración de este proceso de colonización periurbano e interurbano, ya que comienzan a darse las condiciones para que una creciente comunidad campesina y una oligarquía urbana, bien consolidada, puedan ir colonizando tierras, poniéndolas en valor mediante irrigación y creando nuevas explotaciones agrícolas alrededor de una red de caseríos. Mientras, otras poblaciones rurales o alquerías pudieron tener una potenciación o un origen diferente, como un cierto valor militar por su emplazamiento, o representar un enclave importante en la distribución del riego, o la red viaria, etc., pudiéndose organizar sujetos a las obligaciones fiscales comunes, por nuevas emigraciones o inmigraciones o a través de las autoridades político-administrativas.

Este proceso histórico, caracterizado por el efecto disgregador del sistema de irrigación, va a sustentar, principalmente, ya en la etapa final almohade (según datos del Libro del Repartimiento de Orihuela, a finales del siglo XIII) a más de 60 alquerías o núcleos rurales que dominaban una superficie irrigada de más de 44.000 tahúllas $(5.000 \mathrm{Ha}$.), de la que depende toda la comunidad que gravitaba en torno a Madina Uryula (Orihuela).

Por lo tanto, no hay que olvidar que si sobre esta nueva expansión y vertebración de los espacios irrigados en los periodos de taifas, almorávide y, sobre todo, almohade, hay también suficientes evidencias para puntualizar que, en dicha fase de expansión hidráulica y aprovechamiento integral del sistema de regadío, se deben incluir el resto de acequias mayores oriolanas, tanto las de la margen izquierda (casos de las Acequias de Almoravit, Vieja de Almoradí y de Escorratel), como las de la margen derecha (Acequia de Molina y Acequia de Alquibla), todas ellas citadas en el Libro del Repartimiento de Orihuela (12651314) (Fig. 2).

En otros trabajos anteriores hemos analizado de forma más extensa la capacidad de la sociedad andalusí (en su devenir histórico) por utilizar al máximo un espacio limitado, aprovechando integralmente las aguas disponibles. Y, precisamente, a partir del análisis y la confirmación de la estructura fundacional árabe del dispositivo de riegos, es posible determinar que desde el momento en que empieza su expansión decisiva, su construcción está directamente vinculada a la progresiva solución de las dificultades para el asentamiento humano y el desarrollo de la agricultura. Por ejemplo (y de aquí también su singularidad) cómo su propia concepción y diseño básico ya está condicionado desde el principio por la topografía y los caudales ocasionales que descienden por ley de gravedad desde las ramblas hacia el llano aluvial, donde se deben prever desde el inicio de su implantación, para evitar el efecto destructor de las avenidas sobre los campos de cultivo, formas de aprovechar y diseminar estas avenidas ocasionales, en función de la adaptación de la red hidráulica a la doble funcionalidad de riego y drenaje del sistema.

Más aún, gran parte de esta adaptación al medio y aprovechamiento integral del agua, según las coordenadas que ya marcó la colonización árabe, las hemos podido identificar sobre el terreno, en base a un detallado plano del siglo XVIII, a partir del cual hemos realizado la planimetría de todas estas matrices naturales y su yuxtaposición, en forma de abanico, a la red de riego andalusí, transcrita en el Libro del Repartimiento de Orihuela en el siglo XIII. De esta manera, dicha reconstrucción nos permite observar la singular forma de captación, aprovechamiento y uso integral de las aguas provenientes tanto del río Segura como de las ramblas ocasionales (Gea, 1997) (Fig. 3). 


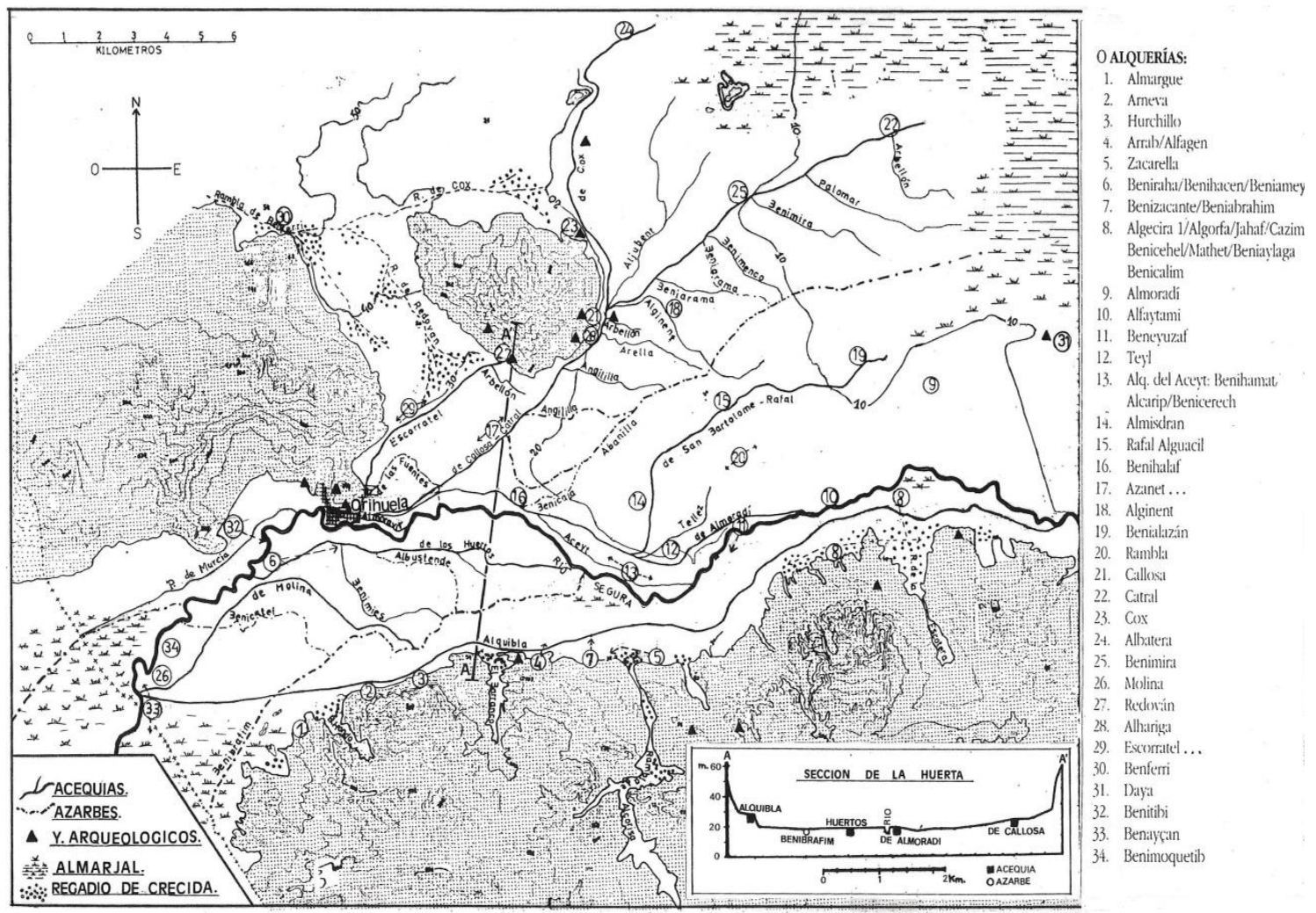

Fig. 2. Acequias y azarbes con nombres árabes del Bajo Segura y disposición topográfica del poblamiento según el Repartimiento de Orihuela (siglo XIII).

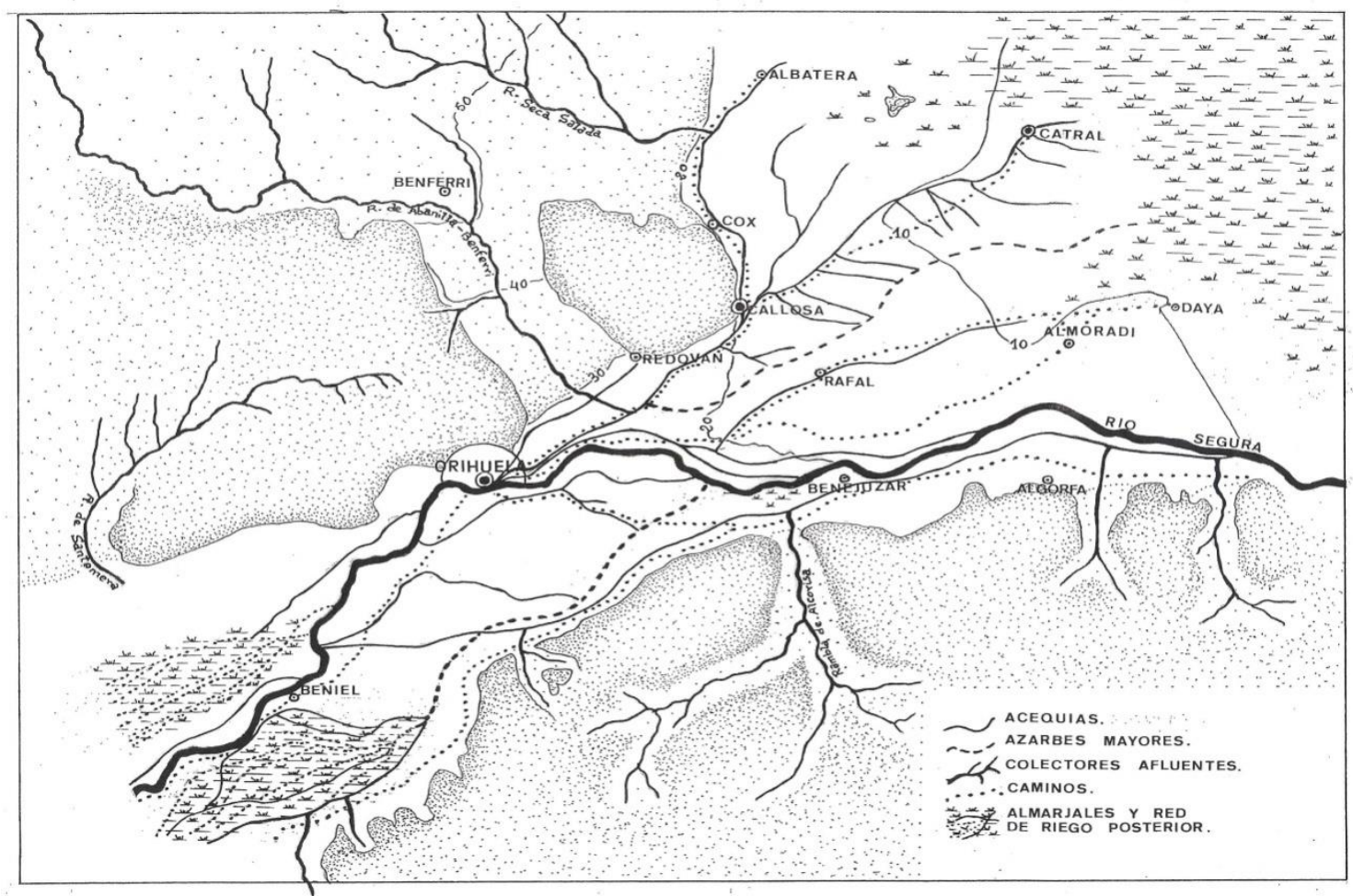

Fig. 3. Matrices naturales de agua del Bajo Segura y su yuxtaposición al dispositivo general de riego andalusí. Interpretación nuestra basada en un detallado plano del siglo XVIII. 
Obsérvese como los valles afluentes descienden a través de la incisión provocada por el colector principal y dónde y cómo se encajan en la red de riego-drenaje. Véanse también la interrelación que se produce entre la red de riego y la red de caminos principales.

Finalmente, una vez determinado el diseño estructural y el funcionamiento del sistema de acequias mayores que irrigaban el alfoz oriolano durante la etapa almohade, es imprescindible tener en cuenta la escala de los perímetros irrigados asociados con su estructura topográfica, o lo que es lo mismo, el aumento estructural de las ramificaciones hidráulicas o brazales de las paradas de la acequia o cauce principal en cada etapa histórica. Antes de documentar esto con un ejemplo específico, interesa saber que el proceso de ocupación agrícola será lento y prolongado, viniendo determinado por el crecimiento de los núcleos poblacionales. En este sentido, pondremos el ejemplo de la Acequia de Molina, cuyo canal principal o acequia, (incluidas algunas arrobas y determinados brazales) en el momento tras la reconquista cristiana (finales del s. XIII) regaba sólo por entonces algo más de 1.500 tahúllas, verificándose, pues, que la Acequia de Molina o de Santa Bárbara coincide prácticamente con las tierras irrigadas de huerta que se reparten en la cuadrilla de los Arrafales de Molina: "quadella de los Arrafales, que son en la ribera del río, así como parte con Molina et con Beniabie” (Repartim. p. 7-8, Torres Fontes, 1988), donde se reparten 1.555 tahúllas, de lo que se puede inferir también que era el espacio de huerta principal que regaba entonces dicha Acequia de Molina. Sin embargo, en el último repartimiento de aguas de esta acequia, que se hizo en el año 1794, podemos contabilizar que, a través del riego de sus diversos brazales y arrobas ramificados en función de sus 20 paradas, "llegaba a regar 8.047 tabúllas en la huerta de Oribuela, con tanda en cada diez y siete dias" (Roca de Togores, 1852) (Véase la Fig. 4).

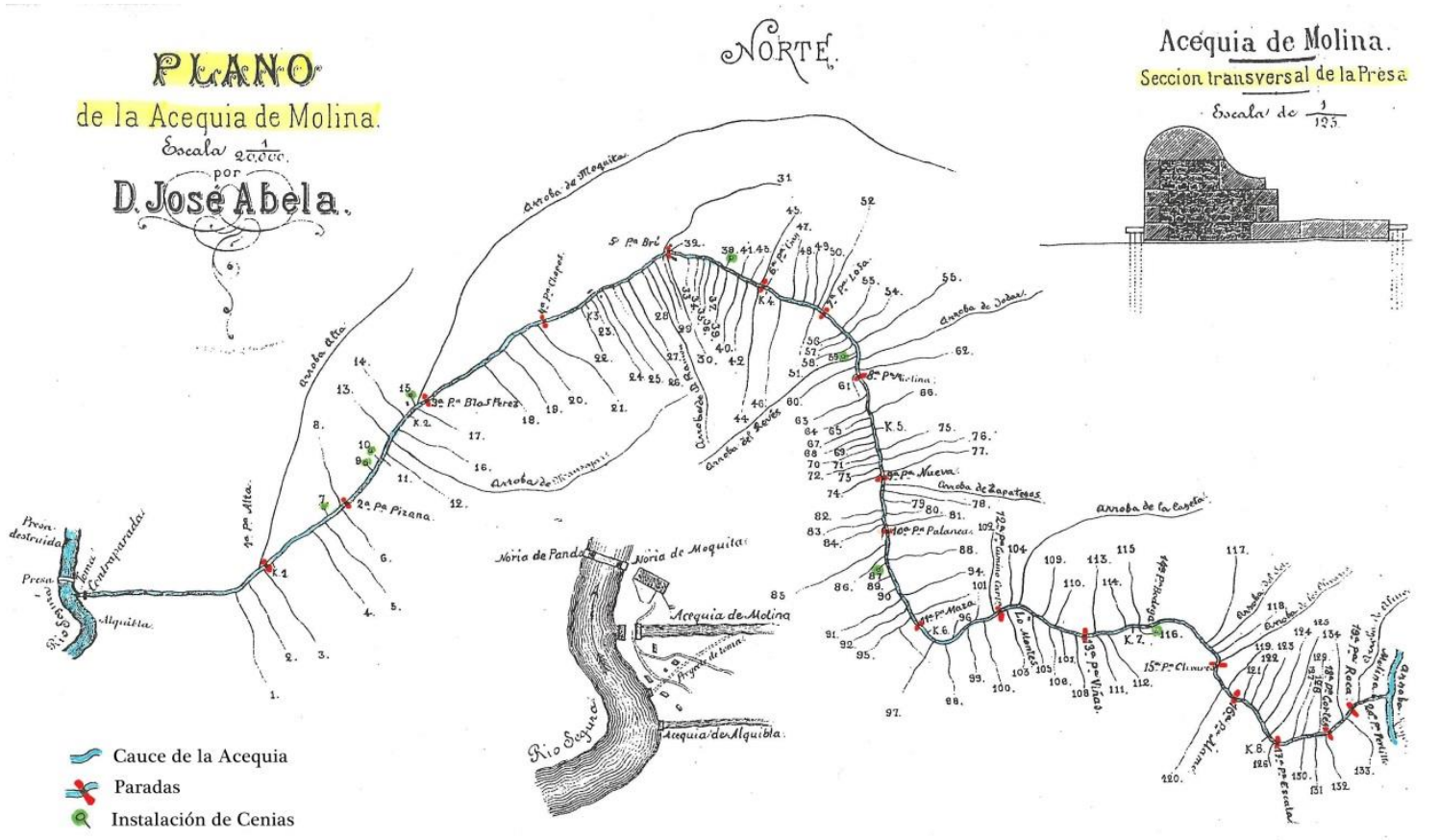

Fig. 4. El sistema de regadío se articula a través de una complicada estructura técnica de esclusas y una red de acueductos que se va adaptando a la ley de la gravedad y a la microtopografía que exige la zona. Todo ello va conformando esta obra maestra de empirismo agrícola que tanta prosperidad ha dado a la zona. Plano de la Acequia de Molina en el s. XVIII. 


\subsection{Principios organizativos y de distribución del regadío tradicional}

Paralelamente al análisis morfológico y de diseño del sistema hidráulico y el perímetro irrigado, hay que distinguir que el regadío histórico presenta otra serie de elementos fundamentales asociables a la sociedad andalusí. Por ejemplo, cabe observar cómo en esta sociedad de regadío comunitaria, la unidad básica es la Comunidad de Regantes: es decir, la comunidad de regantes que riega de un solo acueducto principal, y de la misma manera, en el derecho consuetudinario el agua no corresponde al propietario de la tierra, sino a la propia tierra, y de esta agua el propietario tiene derecho a tomar una cantidad proporcional al área de regadío que posee o gestiona. Estos reglamentos de distribución social del agua reflejan claros modelos histórico-culturales de origen andalusí, que se han ido institucionalizando a lo largo del tiempo, a través de la costumbre y los órganos de poder colectivo.

Además, el espacio hidráulico y la disponibilidad de caudal condicionan los procedimientos de distribución del agua de riego en el sistema. Por lo que, básicamente, dichos procedimientos tratan de dividir proporcionalmente el volumen total del agua disponible que extraen del río los azudes o presas. De ahí que una serie de azudes (en gran parte con emplazamientos de origen andalusí) permitan elevar el agua en los varios sectores del río, para su derivación por la red de riego que forma la estructura técnica del sistema de regadío. Esta estructura técnica, desde el momento que comienza su implantación, por un lado, va generando una capacidad productiva determinada conforme avanza (con parones e incluso retrocesos por causas naturales, guerras bajomedievales, etc.) y, por otro, va imponiendo restricciones físicas al suministro y distribución del agua, creando nuevas regulaciones, como la de los regadíos "indotados", los cuales sólo podían regar con las aguas sobrantes de la red ya establecida (aunque esto se produce ya más tardíamente). Además, el sistema hidráulico está sometido a un orden jurídico que regula su funcionamiento: reglas de tandeo, de prioridades, de deberes comunales, etc.

Con todo, nos interesa aquí subrayar que otro de los rasgos básicos y determinantes del sistema es el de la "proporcionalidad". La proporcionalidad fue el factor organizativo de nuestro sistema desde su origen andalusí. Cada regante recibe el agua en proporción a la cantidad de tierra que posee. Sin embargo, el agua a que se tiene derecho no era una cantidad fija por unidad de tierra, sino más bien una cantidad proporcional que variaba con el volumen del río. Todos los regantes participaban en tiempos de abundancia; y eran igualmente despojados en tiempos de sequía. Esto es muy importante para entender el funcionamiento del sistema.

Una de las ventajas del sistema proporcional -como agudamente ya clarificó T. F. Glick para el sistema de Valencia y de Murcia-Orihuela- era que la distribución equitativa podía estar asegurada sin medidas de tiempo ni de orificios de reparto. Cuando el caudal de agua era abundante, el regante tomaba sin restricciones el agua que necesitaba. Cuando el agua disponible era escasa, se establecía un turno o tanda; y si la cantidad de agua disponible disminuía aún más, el intervalo entre los sucesivos turnos se incrementaba. Pero tampoco en esta eventualidad era necesaria la medida, porque cuanto menos agua se desperdiciara ( $\mathrm{y}$ había penas específicas para asegurar que esto no sucediera), más agua podía usar el regante; éste tenía sólo una determinada cantidad de tierra y no podía regar más de la cuenta sus cosechas, sin dañarlas. Por tanto, el único control necesario para asegurar la igualdad de la distribución era vigilar que no pudiera volver a tomar el agua hasta que todos los demás hubieran agotado su turno (Glick, 1988, 300). 
Así pues, estas normativas consuetudinarias y comunitarias -con las principales fórmulas fijadas desde la colonización árabe-, y la vigilancia socio-institucional, garantizarán la estabilidad del sistema. Ahora bien, a partir de estos principios fundamentales (en donde podemos decir que está la matriz profunda o el ADN del sistema) la ordenación espacial y la gestión del sistema hidráulico van a ir adquiriendo una mayor complejidad, ya que las ampliaciones progresivas de la superficie de regadío en la huerta se van a ir realizando en sucesivas etapas históricas que, a su vez, marcarán también su impronta en el sistema hidráulico y fijarán de forma más estricta (a la normativa general de riego) la distribución del agua y el establecimiento de tandas en cada acequia, con respecto a los procedimientos de la etapa medieval. Todo ello, con especial incidencia durante el siglo XVII y a partir de las nuevas Ordenanzas de Riego de Jerónimo Mingot (Ojeda, 2011) (Fig. 4).

\section{El río Chícamo y el sistema hidráulico de la huerta de Abanilla}

A continuación, como ya se analizó detalladamente en la publicación citada en la introducción (Gea et alii, 2011-12) nuestra investigación ha permitido discernir en la huerta de Abanilla un sistema hidráulico complejo de origen andalusí, con cuyo estudio se empezará a determinar la hidráulica del dilatado territorio de la cuenca del río Chícamo; ríorambla que tiene su origen en la confluencia de varias ramblas y ramblizos de la sierra de Barinas-Cantón, en la parte septentrional del término municipal de Abanilla y sus colindantes de la Comunidad Valenciana. Por lo tanto, vamos a centrarnos ahora en identificar y comprender esta peculiar y compleja obra de ingeniería hidráulica, de origen andalusí, que representa el sistema hidráulico y el espacio irrigado en torno al hisnde $\mathrm{Al}$ Banyala (Abanilla).

Desde el punto de vista hidráulico, el azud del Partidor (situado a unos $5 \mathrm{Km}$. de la población de Abanilla) es la estructura de la primitiva captación andalusí, donde el Chícamo deja de ser río, ya que las aguas no torrenciales que por él discurren son totalmente recogidas y encauzadas para el aprovechamiento agrícola por el dispositivo de riego. En las actas del Concejo de Abanilla hay un dato del año 1561 (Archivo Histórico Regional de Murcia) referente a la construcción de este azud, por un cantero llamado Juan Ochoa. Dicho dique ha tenido que ser restaurado varias veces a través de la historia por haberse destruido en los fuertes torrenciales que se han sucedido. No obstante, lo que sí queda claro por medio de la estructura física del sistema hidráulico que todavía pervive en la actualidad, y de los restos arqueológicos del azud antiguo que todavía existen (de mampostería y argamasa), es que estas estructuras nos evidencian su primera ubicación durante la época andalusí, probablemente durante finales del siglo XI o principios del XII.

Así pues, funcionalmente, la red de regadío comienza en este azud, a partir del cual las aguas se conducen por la margen derecha a través de un canal a cielo abierto, de corta longitud, dirigiéndolas a un primer tramo de galería (actualmente sustituida por una conducción enterrada de tubería), continuando en otro pequeño tramo a cielo abierto que las introducen a una mina perforada en una agreste zona de margas, de corte casi vertical. Hay que señalar que, a semejanza de los cercanos qanāt(s) de la "Font Antiga" de Crevillente, la técnica constructiva de esta galería excavada tiene a su entrada y a su salida un recubrimiento de piedra irregular y argamasa, con arco de medio punto, cuya función es la de consolidar e impermeabilizar la galería en ambos extremos. $\mathrm{Y}$ a lo largo de su recorrido se observan toda una serie de aliviaderos y respiraderos que salen hacia el ríorambla, los cuales se aprovechan para su limpieza, reparación y demás labores de mantenimiento. 
Ahora bien, partir de la salida de esta galería las aguas se vuelven a encauzar a canal abierto, hasta el lugar de la estructura hidráulica llamada "El Partidor", donde por medio de un vertedero de sistema lineal de cinco chorros abiertos, de sección rectangular, con base de pletina de bronce (para mejor ilustración, semejante a un peine), se fracciona el caudal y se dirige a dos acequias distintas: una que recibe 4 chorros (los 4/5 del caudal) que riega la Huerta de Abajo o de Mahoya (del árabe Mabüra= "regado, labrado"), situada en la margen derecha y la otra, con 1/5, que riega el paraje llamado Sahués, en la margen izquierda. La proporción de la división establecida, que se pierde en el tiempo y de la que no tenemos ninguna constatación documental, debió fijarse en función de la proporción de la superficie a irrigar y de los caudales disponibles.

Relacionadas, pues, estas cuestiones, podemos volver a la descripción de la estructura física del sistema, el cual, tras la salida de sus dos acequias "mayores" del Partidor, la que se dirige hacia la Huerta, llamada de Abajo (actualmente con 32 litros por segundo), discurre y va regando las tierras de la margen derecha, a partir del llamado "puente de María la Reina", sobre la rambla de Mascosa; si bien, la otra acequia, la que se dirige a Sahués (con 8 litros por segundo), mediante un desvío desplaza el agua a la margen izquierda por medio de un acueducto, reconstruido en el siglo XVIII por destrucción del anterior, a causa de las fuertes avenidas torrenciales.

Siguiendo con la descripción de los tramos de este mesosistema hidráulico, damos ahora con el primer dispositivo de molienda medieval. De este modo, tras la citada llegada de la acequia mayor al molino del Arco, en las actas del concejo del siglo XVI (antes citadas) se menciona la necesidad de reparar el molino "viejo" a la mayor urgencia, ya que su rotura estaba causando serios perjuicios a la comunidad mudéjar, que tenían que llevar el grano a moler a Orihuela. El concejo también acuerda la prioridad de construir otro nuevo, aguas arriba, para que no se volviera a repetir esta situación tan penosa. De lo que podemos inferir que, en esencia, queda clara también la gestión por parte del concejo de Abanilla del molino, desde al menos el inicio de la Encomienda de la Orden de Calatrava; constatándose, igualmente, una clara instrumentación por parte de dicho concejo (de características señoriales y supervisado por un "comendador") del control de la molienda. A este respecto hay que considerar que el grano de trigo será desde la reconquista cristiana el principal producto de pago de rentas de los dominios señoriales ( $y$, por ende, las encomiendas); y en Abanilla se beneficiaban de sus derechos de molienda, con la acumulación del capital de arrendamiento del molino.

Por consiguiente, conviene hacer un nuevo paréntesis en la descripción del sistema de derivación de aguas de origen andalusí, para subrayar lo que supuso construir este costoso molino de cubo, llamado "del Arco," en el paraje de Ricabacica, cerca de Mahoya, aguas arriba de donde comienzan a ordenarse las terrazas de cultivo. Hay que advertir que dicho emplazamiento estratégico (aunque manteniéndose dentro del trazado de la acequia principal), en el recorrido del canal de riego muestra una orientación de dar prioridad al sistema de molienda sobre el uso agrícola del agua. Algo que, como se ha determinado en el estudio de otros sistemas, va a representar un primer cambio en las prácticas hidráulicas de los sistemas a pequeña y mediana escala andalusíes, que pudo ser una intrusión en la organización del sistema hidráulico andalusí de Abanilla, anterior a la conquista cristiana. Pues, de alguna manera, se establecen ahora de forma institucional unas directrices respecto a los procedimientos legales de los derechos del agua en el sistema, restringiéndose así el uso de agua de la acequia principal a la comunidad de regantes mudéjar. 
Sin embargo, este tipo de transformación no va a variar las bases del modelo organizativo, pues todas las evidencias indican que la yamāa ade Abanilla (la comunidad o aljama islámica de Abanilla) siguió aplicando los procedimientos colectivos de riego preexistentes de forma autónoma y de acuerdo con las prácticas y derechos de agua musulmanes, si bien su espacio agrario debió integrar en mayor medida el cultivo del cereal entre los cultivos de autoconsumo y comerciales (especialmente la parte destinada a su comercialización en los mercados de la ciudad de Orihuela), debido a que la renta feudal que pagaban sus tierras, que se debía efectuar bajo la forma de pago en medidas de grano.

Por último, y volviendo tras este paréntesis al trazado final de la Acequia Mayor de la Huerta de Abajo (tras ser aprovechada la fuerza de sus aguas por el molino "viejo" o "del Arco", destruido por unas fuertes riadas), dicha acequia se dirige, tras pasar por el arco de la rambla de Balonga, a otra galería o mina (que se tuvo que construir en la década de 1950, porque la anterior se derrumbó), siendo a partir de aquí donde verdaderamente empieza el riego de la Huerta de Abajo, en Mahoya, a través de la acequia mayor, distribuyéndose por tandas en cada una de las "paradas", desde donde parten los distintos brazales. Estas paradas reciben cada una su nombre, relacionado con el topónimo del lugar o con el de alguna conocida heredad o renombrado propietario. Sabemos que el nombre histórico de algunas paradas ya está constatado en escrituras del siglo XVIII: de Benical, de las Cañas, del Dembla, de la Ermita, de la Nava, del Chorro, de los Frailes, etc., terminando en la de la Arena, sito en la carretera de Fortuna, al comienzo del olivar (Fig. 5).

Pero, además de esta descripción de las paradas y del dispositivo de brazales de riego, se puede hacer otra relación de nombres de paradas que cabe relacionar, tanto con el sistema original de riego de la Acequia Mayor de la Huerta de Abajo, como con la denominación de los parajes o pagos de la huerta original andalusí, los cuales parecen haber conservado su toponimia de raigambre árabe. Entre estos podemos citar los parajes y paradas del Bayá o Bayad, del Chorro, de Benical, del Albellón, de Bainaó Beina, de Mayola, etc.

Ahora bien, en este último trayecto de la acequia mayor, donde el flujo del agua se regulaba ya cuidadosamente para planificar el regadío hacia las terrazas de cultivo, se ha podido rastrear la presencia de un antiguo emplazamiento de molino, del que sólo queda su probable toma en la parada del Chorro y las trazas de su ubicación original, al comienzo del paraje del Gema. Hay que hacer notar que el emplazamiento de este molino (diferente del molino "Viejo", tanto respecto a la prioridad en el uso del agua como a su inserción dentro del perímetro de terrazas irrigadas), si nos atenemos a las bases estructurales y sociales de los sistemas hidráulicos a pequeña y mediana escala andalusíes estudiados, pudo formar parte del diseño original del sistema. Pudiendo indicarnos, además, que haya habido alguna variación en el trazado de la Acequia Mayor a través del tiempo, con el fin de dar riego a zonas de cota ligeramente superior y que este molino dejara de funcionar cuando se efectuó tal reforma, al dejar de ser casi continuo el paso del agua.

Por otra parte, resulta particularmente importante, advertir en una observación atenta de los documentos del siglo XVIII, una serie de principios organizativos para la distribución del agua, en los que se detalla con precisión una clara relación entre el riego de los bancales aterrazados de la huerta con su correspondiente dotación del agua de riego, cada veintidós días, expresada en horas y sus fracciones. Por lo que en este modelo de organización del regadío, fue ya a finales del siglo XIX y principio del XX cuando la dotación del agua se separa de la tierra, contraviniendo la normativa consuetudinaria específicamente andalusí y mudéjar. $\mathrm{Y}$, claramente, tras esto, comenzarán a introducirse en la nueva organización de los riegos una serie de resoluciones que cambiarán en parte el modelo primitivo anterior. 


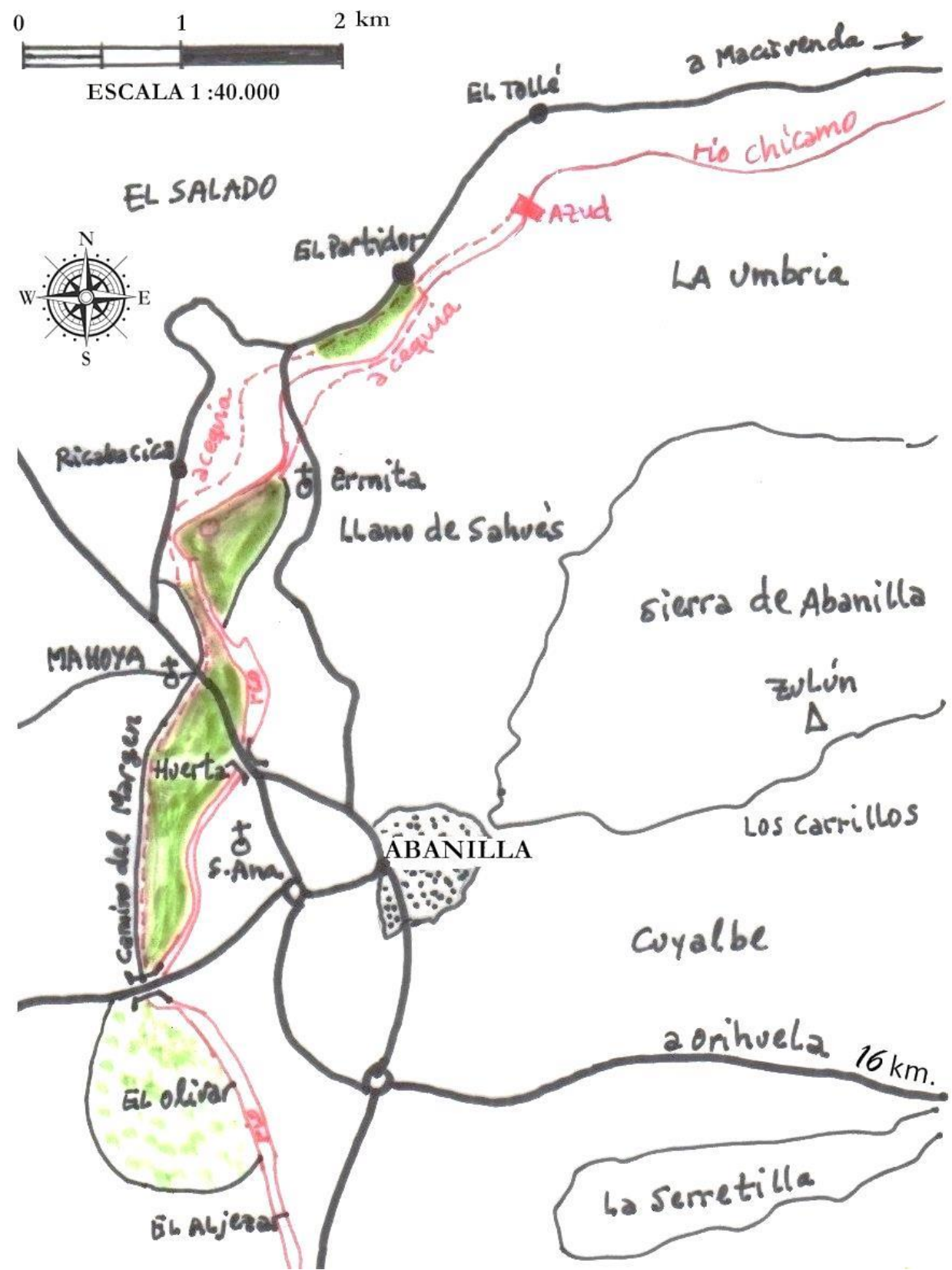

Fig. 5. Plano del Sistema Hidráulico y la Huerta de Abanilla.

Finalmente, cabe abordar, aunque manteniendo una suficiente prudencia, la reconstrucción espacial de la estructura andalusí de la huerta de Abanilla que, según nuestra hipótesis, ocupaba: por la margen derecha el área comprendida entre El Partidor y el final del olivar, en el paraje denominado El Bureite, lindante con el Aljezar. Y, por la margen izquierda, Sahués, que comprende desde la salida del acueducto de paso por el cauce del río Chícamo hasta el paraje de Muzarra, frente a Mahoya; haciendo la salvedad de que la Huerta de Arriba (desde El Partidor al arco de María la Reina), su caudal y sistema de riego está incluido con el de Sahués.

A este respecto y siguiendo la documentación histórica más fiable, pensamos que como base de cálculo debemos partir de los datos dados en el Diccionario de Madoz, en 1850, en donde se cifra el espacio agrario perteneciente al término de Abanilla con "340 fanegas de riego, siendo algo más de la mitad de olivar". Con estos datos podemos hacer un cálculo 
estimativo sobre la superficie regable a tandas regulares con el agua del Chícamo en esta época, despreciando las pequeñas superficies regadas en otros lugares como Barinas y los arrabales de Abanilla, sin incluir Mafraque y el Paúl, por regarse estos con aguas de escorrentía, de flujo no constante. Dado que el sistema normal de tandas en la Huerta empezaba en la parada de Benical y terminaba en la de la Arena (camino de Fortuna), donde empieza el olivar, que sólo se suele regar tres veces al año, las 340 fanegas corresponden a 2.040 tahúllas de $1.118 \mathrm{~m}^{2}$. Ahora bien, si el olivar de regadío suponía algo más de la mitad de la superficie regable, estimando esta proporción en el $65 \%$, su extensión era de 1.326 tahúllas, quedando 714 para la Huerta y Sahués. Y teniendo en cuenta la proporción del reparto del agua en el partidor, de $1 / 5$ Sahués y 4/5 la Huerta de Abajo, saldrían 571 tahúllas para la Huerta, con tandas de 22 días (528 horas), lo que corresponde a una proporción muy aproximada a una hora por tahúlla; en Sahués, 143 tahúllas con tandas cada 18 días (432 horas), lo que da una proporción de 3 horas por tahúlla.

Es obvio, por tanto, que el territorio regado en la actualidad varíe respecto al primitivo de época andalusí-mudéjar, ya que se nota con cierta evidencia que se han ido transformando terrenos baldíos en regadío, aterrazando y aplanando pequeños declives. Pero, además, en lo que respecta a las características estructurales actuales, hay que señalar que el sistema de riego en Sahués establece las tandas cada 18 días, pero con el caudal asignado es dificultoso el riego tradicional a manta, por lo que hay construidas una serie de balsas en las que se acumula el agua cada tanda, para utilizarla después. Una de las balsas más antiguas, probablemente relacionada con el sistema original andalusí, está construida en una excavación sobre terreno impermeable de margas y cerrada en dos laterales por obra, cuyas reformas nos impiden determinar su exacta antigüedad, es denominada como "la balsa del Peso", sin que tengamos referencia de su denominación, más que por la tradición.

A modo de conclusión, podría afirmarse (y en todo ello iremos abundando en nuestro estudio más adelante) que la continuidad poblacional de la Comunidad rural andalusímudéjar de Abanilla, y su adaptación al orden feudal en esta huerta altamente productiva de Al-Andalus, permite contextualizar un caso modélico (aunque con sus peculiaridades), tanto en lo que se refiere a la continuidad física y de uso del sistema hidráulico andalusí, como en lo que se sabe que van a representar los molinos dentro de estos sistemas y en la evolución del feudalismo, especialmente en los territorios aragoneses y catalanes, donde se iniciará toda una reorganización tecnológica general de los molinos rurales colectivos andalusíes, que conducirá a la intensificación y expansión de nuevos molinos en los entramados de estos complejos hidráulicos, como han descrito a la luz de las dinámicas (y lógicas variaciones) de cada sistema, M. Barceló et al. (1988) en Cataluña, H. Kirchner (1997) en Mallorca, S. Selma (1991) en los sistemas hidráulicos de montaña de la Serra d'Espadà, Castellón, y J. Torró $(1990,2007)$ en la montaña del norte de Alicante. (Véanse fotos del sistema hidráulico de Abanilla: Figs. 6, 7, 8, 9 y 10).

\subsection{Marco organizativo y distribución social del agua en el sistema hidráulico y la huerta de Abanilla. La impronta andalusí}

Ya hicimos referencia en una publicación anterior a cómo la villa y castillo de Abanilla en época islámica estaban asociados ya a su amplio espacio de huerta de Mahoya-Sahués. Y todo lo que ello implicaba respecto a su gran perímetro agrario, el complejo sistema de regadío que hemos descrito, la importante carga poblacional y su jerarquización administrativa, dependiente de la gobernación de Orihuela, al menos en la última ordenación almohade (Gea et alii, 2011-12). 
No obstante, la constatación estructural y organizativa de la huerta de Abanilla puede también verificarse, tras la historia y acontecimientos políticos del señorío de Abanilla, a partir de la conquista cristiana de mediados del siglo XIII y la primera documentación del siglo XIV.

$\mathrm{Y}$, efectivamente, es significativo el privilegio dado por Alfonso X al concejo murciano, en 1267, otorgándole que las aguas de las acequias sean repartidas entre los cristianos y los musulmanes de forma comunal y en proporción directa a la tierra que cultivan, señalando días y horas de riego; esto no es ni más ni menos que el sistema de las tandas, con reparto del agua circulante en proporción a la superficie a irrigar. Ahora bien, esta nueva situación unificaba y daba continuidad a la organización del perímetro huertano planificado en época andalusí, permitiendo cierta libertad de acción a las familias campesinas mudéjares en la autogestión colectiva y productiva del sistema de regadío, lo que confería un alto grado de estabilidad a la comunidad de riego mudéjar dando seguridad y facilitando sus intereses comunes.

Para confirmarlo contamos con una fuente directa, como son las ordenaciones de Arnau Torrellas, confirmadas por Pedro el Ceremonioso en 1375:

"...que anassin a regar llurs Camps de nit, llevat dels moros de Favanella (Abanilla), Crevillent, la Vall d'Elda, d'Elx i Alacant, que regaven llurs terres per tandes i que, per tant, podrien anar a regar quan els toqués, sempre que ho notifiquessin prèviamente al senior del lloc i no sortissin de llurs Camps" (Ferrer i Mallol, 1988).

Por tanto, sobre esta base organizativa y social original de época andalusí, cuya pervivencia con pocos cambios (en lo que afecta a los elementos estructurales y organizativos del sistema) podemos hacerla extensiva a la yamā’a de Abanilla (la aljama mudéjar que es expulsada en el siglo XVII), es sobre la que cabe interrogarse en la consideración del papel transformador y estabilizador que tiene el sistema hidráulico sobre el territorio y sobre el aumento de la productividad de la tierra y, por ende, de la demografía que puede asumir dicho perímetro irrigado original.

A grandes rasgos, este tipo de agrosistemas de montaña a mediana o pequeña escala del mundo rural andalusí, entre los que desde nuestro punto de vista podemos encuadrar los articulados en el valle del río Chícamo, han sido definidos como los caracterizados por un específico modelo de agricultura irrigada, creado y gestionado por una sociedad campesina de base clánica y agnaticia, y que eran principalmente el resultado de las inmigraciones bereberes a Al-Andalus (Bazzana y Guichard, 1981; Bazzana et al. 1988; Barceló, 1988; Barceló et al. 1996). No obstante, en nuestro caso, ya pusimos de relieve la probable conexión del espacio irrigado de Abanilla con asentamientos e inmigraciones de comunidades tribales beréberes. Y, ciertamente, se destacó el alto control local que tenía la comunidad campesina en la organización de su trabajo y en la gestión del regadío (Gea, Moñino et al., 2011-12).

En este sentido, T. F. Glick (2007) a propósito de ciertas fatwàs (dictamen judicial) medievales, en el norte magrebí beréber y en la Granada Nazarí, también ha advertido sobre la simplicidad en los procedimientos de reparto de agua y de tanda o rotación en estos modelos de irrigación de origen tribal, en donde su principal propósito estructural y organizativo consiste en reducir la ambigüedad en el reparto del agua, de modo que lo único que hace falta para mantener al mínimo el hurto de agua es un control informal, basado en normas de cooperación y de contacto directo entre los regantes. 

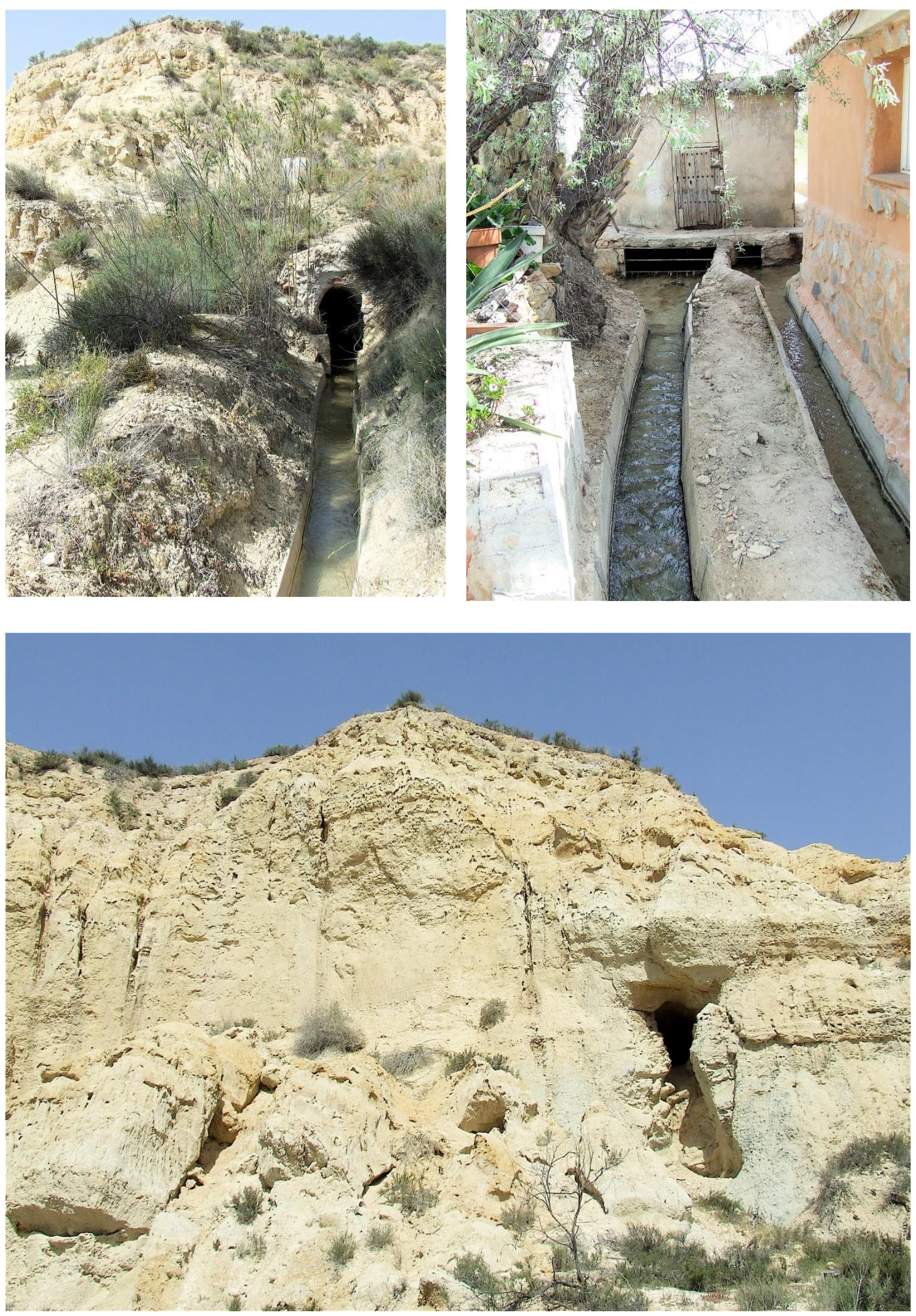

Figs. 6, 7 y 8. Arriba a la izquierda, canal que viene del azud del Partidor y dirige las aguas a la galería o mina. Arriba a la derecha, las dos acequias ya encauzadas que riegan la Huerta de Sahués y la Huerta de Abajo o de Mahoya. Abajo, aliviadero y respiradero de la galería. 


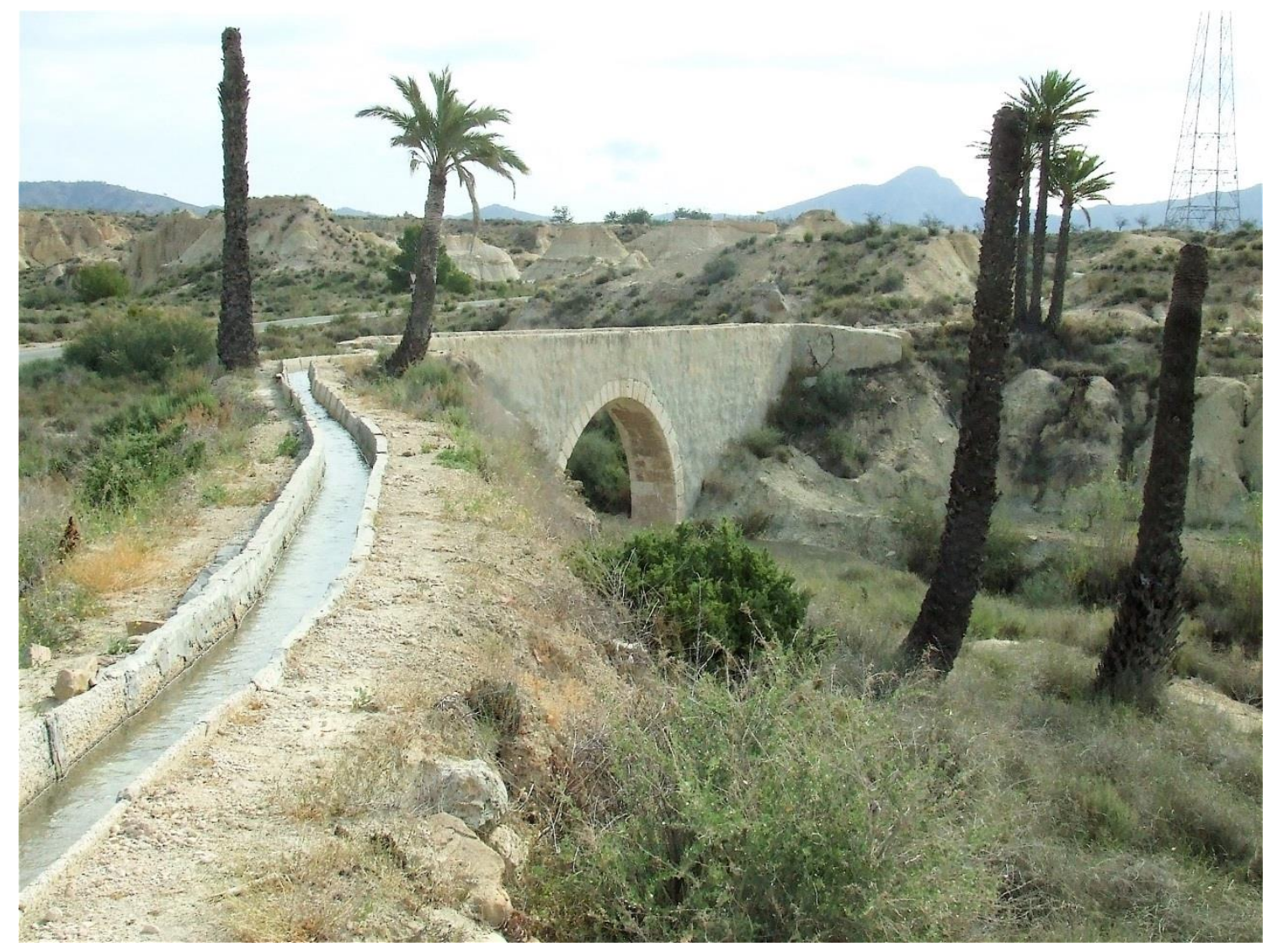

Fig. 9. Acequia que discurre hacia el Arco de $\mathrm{M}^{\mathrm{a}}$ La Reina (acueducto).

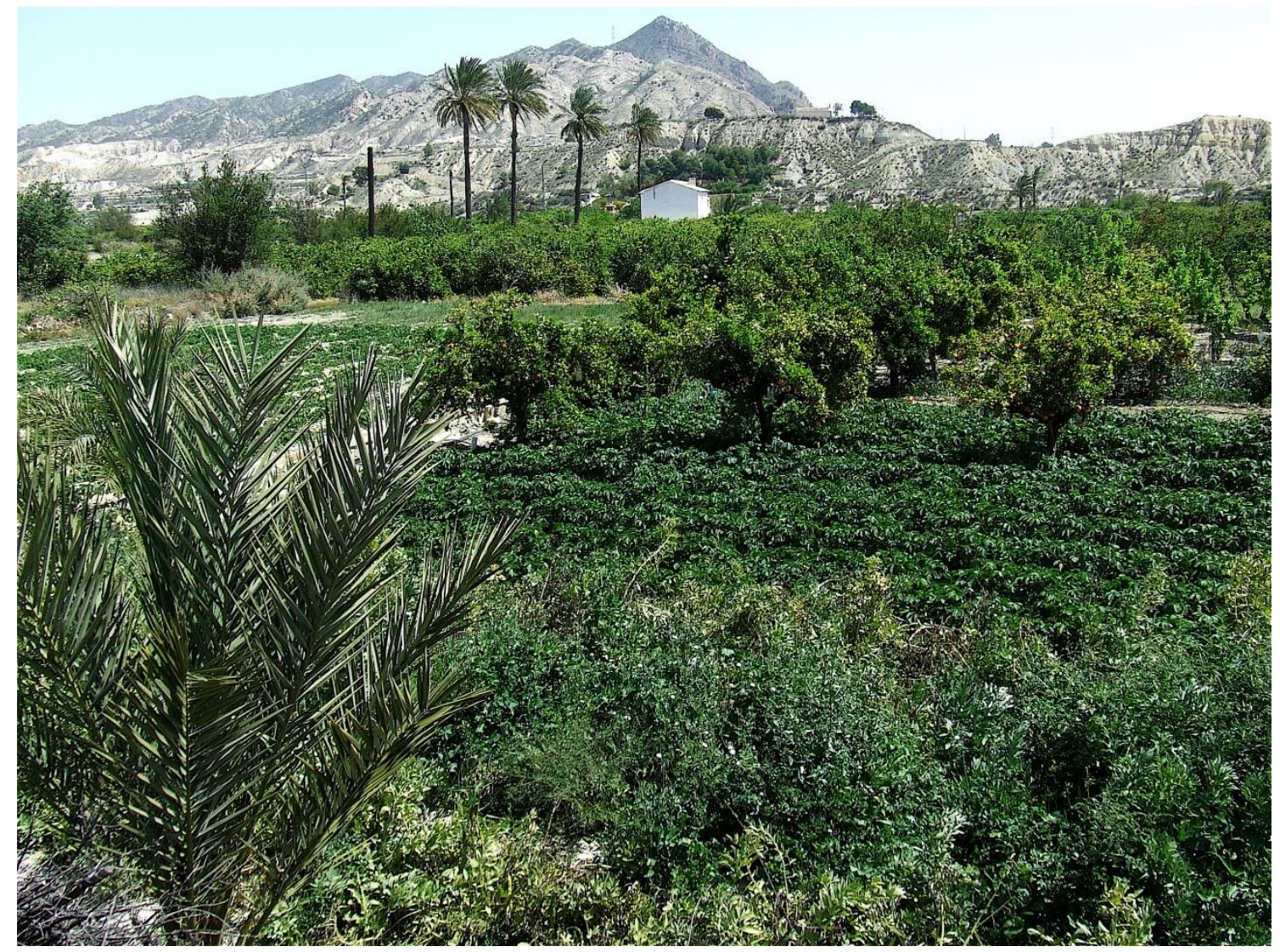

Fig. 10. Vista general de la Huerta de Mahoya. 
Concretamente, la fatwà de Kairuan de inicios del siglo XI, describe un curso de agua que es patrimonio indivisible de un clan, y en ella se especifica que ningún miembro individual puede reclamar la posesión de una determinada porción de agua. Y en lo que respecta a la fatwà granadina, se describe como cada una de las cinco acequias del hisn Šîrûr se organizaba en rotaciones desde la cabecera hasta la cola del canal, con horas fijas de suministro, supervisándose directamente por los regantes en función de su turno de riego.

Dentro de este contexto, en la huerta de Abanilla el tipo de división y reparto de agua tradicional funciona de acuerdo a la costumbre y está relacionado en función de cómo se medía el tiempo cuando no existían relojes mecánicos. Es decir, el tiempo era una realidad astronómica y social repetida periódicamente, un ciclo de acontecimientos que se ajustan al periodo del día (desde la salida a la puesta del sol, aproximadamente 12 horas). Y, en este sentido, T. F. Glick ya puso en claro la importancia del sistema duodecimal de medida en el sistema de medición del agua en la Huerta de Valencia, sugiriendo "que las asignaciones de filas de las acequias de la Huerta de Valencia no tengan nada que ver con su turno, sino que simplemente representen proporciones, según un sistema duodecimal basado en el cuadro de doce”. Señalando además, que es la característica más notable del sistema de medida en el Ghūta o Huerta de Damasco (Siria). Pero también en el sur de Irak, en donde la unidad de base de la medida del agua es el Waqt (tiempo), que significa cada período desde la salida a la puesta del sol o de la puesta a la salida, aproximadamente doce horas. Y de idéntica manera, nosotros consideramos que también en la base original de estos procedimientos de medición puede estar la clave del periodo rotativo específico del sistema de Abanilla. Pues en la partición del río en Abanilla, el río Chícamo está dividido en 22 días de agua, expresados en horas o fracciones.

Por otra parte, como ya se ha indicado anteriormente, otro de los elementos esenciales de nuestro sistema es, según hemos podido rastrear en documentos a partir del siglo XVIII, la correlación media entre la superficie correspondiente a cada parcela de tierra y el agua, determinándose también una partición por horas en el suministro. De hecho, la unidad de medida de riego es de una hora por tahúlla $\left(1.118 \mathrm{~m}^{2}\right)$, aproximadamente, lo cual hace que se pueda argumentar, por analogía, que dicha partición y unidad de medida, (basada en horas) también formaba parte de un modelo tipo que estaba muy extendido entre los países islámicos desde época medieval, donde la medida tipo del agua es el qĩrät, una medida proporcional que, aunque varía en valor de un sitio a otro, equivale en la mayoría de los lugares a una hora (Glick, 1988).

Otro hecho destacable del diseño y la morfología estructural del sistema y el área irrigada de la huerta de Abanilla es la construcción, en el perímetro irrigado por la acequia de Sahués, de una balsa o alberca llamada del "Peso", cuyo mismo nombre parece indicarnos su estrecha relación con la planificación de la distribución social del agua en dicha zona de huerta, pues según pudimos averiguar en la zona, debido al reducido caudal de la acequia que la abastece, era necesario ir embalsando el agua hasta que estuviera llena, lo que por una parte facilitaba el riego a manta y, por otra, permitía determinar así según su llenado el agua correspondiente a cada familia propietaria.

Ahora bien, lo que más nos interesa resaltar aquí es la solución técnica y la naturaleza reguladora que representa esta balsa o alberca en el sistema de Abanilla. Pues tanto su posible funcionalidad estructural como su vinculación con la distribución volumétrica y social del agua la encontramos aplicada en sistemas hidráulicos de montaña vinculados a asentamientos campesinos desde el Magreb al Masriq (Bouderbala, 1984, y Ron, 1985, 
1995). Sin olvidar su relación y semejanzas con algunos de los sistemas y técnicas hidráulicas que se difundirán ampliamente por Al-Andalus a partir de la conquista musulmana (Kirchner, 2003, y Navarro, 1993).

No obstante, ante este tipo de pautas específicas de alternancia en el riego, en función del orden en que están establecidas las parcelas al principio o al final del sistema hidráulico, hay que destacar otro de los rasgos que caracterizan al sistema tradicional de riego de Abanilla. Pues en este sistema las explotaciones reciben el agua en el orden en que están situadas a lo largo de las acequias, desde la cabecera a la cola, pero especificándose también que hay turnos de riego que empiezan en la cola de la acequia, terminando en su cabecera: o bien como nos indicaron los regantes según el turno del "agua que baja" o el del "agua que sube".

Sobre la implantación de este tipo específico de elementos, relacionados con la manera de organizar el regadío, hay que reconocer que han sido puestos por M. Barceló en relación con los métodos y reglamentos de la agricultura paleo-beréber y beréber de "microentorno"; de acuerdo con lo que sabemos de los estudios realizados por B. D Shaw en el contexto de la irrigación del valle de Lamasba (actualmente Aïn Merwana, Argelia) y a propósito de la lectura del célebre documento epigráfico africano del siglo III (grabado en piedra y con texto en latín) conocido como el reglamento o el decreto de Lamasba, en el que básicamente se documenta un prototípico mesosistema presahariano de terrazas irrigadas -organizadas por grupos tribales- desde el punto de captación de una fuente a partir de la cual los canales de riego distribuían el agua por las parcelas cultivadas.

Sobre esta base, y pensamos que de forma muy similar al mesosistema de Abanilla, las parcelas aterrazadas recibían el agua secuencialmente, especificándose una fecha precisa para cada turno de riego y precisándose un tiempo de agua expresado en horas y medias horas. Si bien, el regadío se efectuaba en dos turnos diferentes, que se refieren al aqua descendens o al aqua ascendens, utilizándose sucesivamente los mismos canales o acequias de riego.

A este respecto, M. Barceló (1996) infiere una posible relación con esta específica organización del regadío en relación con su estudio sobre el sistema de qanat(s) de la "Font Antiga" de Crevillente (población muy cercana a Abanilla), indicando que esta regulación de la distribución de agua entre regantes en los términos ascenderé y descenderé referidos al agua se asemeja mucho a la distinción que le hicieron los regantes de Crevillente sobre el riego por turnos entre "l'aigua que pujava" y el "l'aigua que baixaba" o el agua que subía y el agua que bajaba. Señalemos a este respecto, como también parece deducirse en el caso del sistema de Abanilla, que no se trata de ningún tipo de medida, sino una inversión de los turnos de reparto con la indicación de que el "agua que baja" es el turno de riego que se establece a partir del punto de origen del agua, y al contrario en el turno del "agua que sube". Al tiempo que deduce que es esta "una forma de asegurar que los regantes más alejados del punto de agua tengan adecuadas compensaciones por las pérdidas de agua durante el trayecto -por filtración, evaporación, mengua de velocidad, etc.-, incluso por la imposibilidad de acceder al agua por posibles pérdidas de caudal durante el verano, por ejemplo". Por tanto, aunque hay que señalar que sobre esta cuestión se han propuesto diversas interpretaciones, según nuestra experiencia, y así lo proponemos en nuestro trabajo, la descrita anteriormente es la más acertada.

Finalmente, otro de los aspectos que cabe verificar, dentro del ámbito estructural de la huerta de Abanilla es el de las reducidas proporciones de los bloques de terrazas y el de la igualdad minifundista (aunque mejor sería hablar de microfundismo) de las unidades de 
explotación, que en la actualidad podemos valorarlo en escasas extensiones de 5-6 tahúllas por parcela, hasta parcelas de media tahúlla, siendo la media muy indeterminada, aunque se puede estimar en parcelas de 1,5 tahúllas. Estos rasgos morfológicos del sistema son también muy característicos en la irrigación de montaña tribal del Magreb $y$, presumiblemente, contribuyeron a incrementar todavía más la autonomía en los procesos de trabajo y en el control y uso del agua por parte de estas comunidades campesinas organizadas en origen genealógicamente. Aun así, sin otras evidencias, es muy difícil observar la evolución y desnaturalización que se iría produciendo, tras la adaptación a los cambios de la dinámica feudal, de las estructuras de propiedad musulmanas, cuyas unidades de explotación se conformaban en función de la familia extensa o los linajes. Ahora bien, de lo que no hay lugar a dudas es del proceso de atomización que se fue produciendo con posterioridad a la expulsión morisca de 1609 y la nueva instalación de colonos cristianos "ex novo" en la zona, hasta la actualidad (Fig. 10).

\section{Referencias}

Barceló, M. et al., (1988): Arqueología medieval. En las afueras del "medievalismo", Barcelona, Crítica.

Barceló, M. (1988): Vísperas de feudales. La sociedad de Sharq al-Andalus justo antes de la conquista catalana. España. Al-Andalus. Sefarad: Sintesis y nuevas perspectivas, 99-112, Salamanca.

Barceló, M.; Kirchner, H. y Navarro, C. (1996): El agua que no duerme. Fundamentos de la arqueología bidráulica andalusí. Ed. El Legado andalusí, Granada.

Bazzana, A. y Ghichard, P. 1981): "Irrigation et société dans l'Espagne Orientale au Moyen Age", en L'Homme et l'eau en Méditerranée et auProcheOrient, II, Lyon, pp. 115-140.

Bazzana, A.; Cressier, P. y Guichard, P. (1988): Les châteauxruraux d' al-Andalus. Madrid, Casa de Velázquez.

Bouderbala, N. (1984): La Question bydraulique. Rabat.

Espinar, M. (1990): Población y agricultura de una alquería almeriense en los siglos XII y XIII. Almería entre dos culturas. Siglos XVIII al XVI, almería, Instituto de Estudios Almerienses, 187-207.

Ferrer Mallol, M. T. (1988): Les Aljames Sarraïnes de la Governació d'Oriola en el segle XIVConsell Superior d’Investigacions Científiques - Institució Milá i Fontanals.

Gea, M. (1995): La construcción del paisaje agrario en el Bajo Segura. De los orígenes hasta la implantación de la red de riego-drenaje en el Alfoz oriolano, Alquibla, nº1 (Revista de Investigación del Bajo Segura), 65-99. 
Gea, M. (1997): La formación y expansión decisiva de la Huerta de Murcia-Orihuela. Un enfoque desde la perspectiva de la Orihuela Musulmana (siglos VIII-XIII), Alquibla, n³, $155-217$.

Gea, M.; Moñino, R.; Marín, P. y Marco, E. (2011-2012): Los regadíos medievales y su evolución bistórica en el Bajo Segura. Poblamiento, poder social y comunidades campesinas. Monografía perteneciente a "Cuadernos de Historia y Patrimonio Cultural del Bajo Segura, n 4-5".

Glick, T. F. (1988): Regadío y sociedad en la Valencia medieval, Valencia.

Glick, T. F. (2007): Paisajes de conquista. Cambio cultural y geográfico en la España medieval. Universidad de Valencia.

Kirchner, H. (1997): La construcción de l'espai pagès a Mayûrga: les Vals de Bunyola, Orient, Coanegra i Alaró, Palma de Mallorca, Universitat de les Illes Balears, 1997.

Kirchner, H. (2003): Májil: a type of hydraulic system in Yemen and in al-Andalus. Proceedings of the seminar for Arabian Studies, 33, 143-155.

López, J. y Martín-Caro, F. (1989): Organización, distribución y problemas derivados de la administración del agua en Almería y su vega en los años anteriores a la conquista, $A Z A$, II, 1017-1032.

Navarro Romero, C. (1993): De la Kura de Tudmir a la encomienda de Socovos. Liétor en los siglos X-XV. IV Congreso de Arqueología Medieval Española, Actas II, 525-534, Alicante.

Ojeda, J. (2011): Evolución de las tandas de riego en Orihuela. Cuadernos de Geografía, 89: 23-48. Valencia.

Pocklington, R. (1989): Observaciones sobre el aprovechamiento del agua torrencial para la agricultura en Murcia y Lorca durante la época árabe. Avenidas fluviales e inundaciones en la cuenca del Mediterráneo, Alicante, Instituto Universitario de Geografía, 395-401.

Roca de Togores, J. (1852): Memoria sobre los riegos de la buerta de Oribuela.

Ron, Z. Y. D. (1985): Development and Management of irrigation Systems in mountain regions of the Holy land. Transactions of the Institute of British Geographers, 10: 149-169.

Ron, Z. Y. D. (1995): Sistemas de manantiales y terrazas irrigadas en las montañas mediterráneas. Agricultura y regadío en al-Andalus. Sintesisy problemas, Granada, 383-403.

Rubiera, M. J. (1985): La Taifa de Denia. Instituto Juan Gil-Albert, Diputación de Alicante.

Selma, S. (1991): El molí hidràulic de Farina i l'organització de l'espai rural andalusí. Dos exemples d'estudi arqueològic espacial a la serra d'Espadà (Castelló). Mélanges de la Casa de Velárquez, 27: 65-100.

Torres Fontes, J. (1988): Repartimiento de Oribuela, Edición de la Academia Alfonso X el sabio, imprime: Sucesores de Nogués, Murcia.

Torró, J. (1990): Poblament i espai rural. Transformacions históriques, Valencia. 
Torró, J. (2007): Vall de Laguar. Asentamientos, terrazas de cultivo e irrigación en las montañas del Shaq al-Andalus: un estudio local. Recerques del Museud'Alcoi, 16, 151-182.

Watson, A. M. (1998: Innovaciones en la agricultura en los primeros tiempos del mundo islámico, Granada. 